\title{
CURRENT THEME
}

\section{Towards A New Mental Health Act}

C.L. Narayan*, Rajiv Jaiswal**, Deepshikha**

*Consultant Psychiatrist, Gaya, ** SRHC Hospital, Narela, New Delhi

\section{INTRODUCTION}

Mental health legislation was first enacted in India in 1858 three separate Acts - (1) The Lunacy (Supreme Court) Act, 1858 relating to judicial inquisition as to lunacy in presidency towns; (2) The Lunacy (District Courts) Act, 1858 relating to proceedings outside presidency towns; and (3) The Lunatic Asylums Act, 1858 relating to confinement of lunatics in asylums. These were based on two English Acts namely the English Lunacy Regulation Act, 1853 and the Lunatics Act, 1853 ${ }^{1}$. The Indian Lunacy Act, 1912 was enacted to amend and assimilate the law relating to custody of lunatics in India with the English law on the subject and to re-arrange and consolidate as far as possible the whole law relating to lunatics (Statement of Objects and Reasons of the Indian Lunacy Bill, 1911).

After Second World War the Universal Declaration of Human Rights was adopted by the UN General Assembly to ensure inherent dignity and the equal and inalienable rights of all people. India was a signatory to the Declaration. The need was felt to replace the Indian Lunacy Act, 1912 and the Indian Psychiatric Society (IPS) realized the need to enact new law in this regard and submitted a Draft Mental Health Bill to the Government of India in 1950.Dr. B.A. Bhagwat took active part in preparation of the draft. In 1978 a Mental Health Bill was introduced in the Lok Sabha and was later referred to a JPC headed by Dr. Sushila

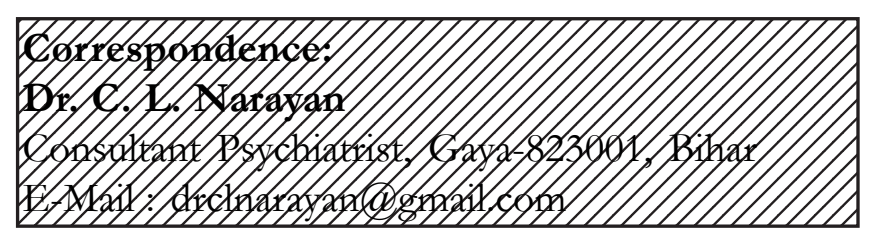

Nayyar. The Bill could not be considered due to dissolution of Lok Sabha. The Bill was again introduced in 1981 in the Rajya Sabha and again referred to a JPC headed by Shri Sukhdeo Prasad, M.P. In 1982, National Mental Health Programme was launched by the Government of India. In 1983 Indian Psychiatric Society voluntarily submitted a memorandum to the JPC and Dr. Jaya Nagaraj, the then President of IPS and Dr. A.B. Dutta ${ }^{2}$ represented the IPS before the JPC. The JPC, which was reconstituted in 1985, submitted its report in May 1986. After being passed by both houses and receiving the Presidential assent, it became Mental Health Act, 1987 in May 1987. It took another three years for the Central Government to frame The State Mental Health Rules, 1990 and The Central Mental Health Authority Rules, 1990. The Government took a further period of three years to issue notification that the Mental Health Act, 1987 would come into force in all States and Union Territories from April 1, 1993. Because of a large number of very complicated procedures, defects and absurdities in the Act and also in the Rules, it can never be implemented properly ${ }^{3}$. The National Human Rights Commission observed in 1999 that the Act was not implemented in many States even in 1999. The Indian Psychiatric Society voluntarily submitted its recommendations on mental health legislation to the Government of India in January, 2001 urging upon the Government to declare its mental health policy and to repeal the Mental Health Act, 1987 by a new Act based on the mental health policy, modern concept of 
psychiatry and recommendations of the international bodies and the IPS. After occurrence of Erwadi tragedy in August 2001, the Supreme Court of India initiated a PIL (WP no.334/2001) and a second PIL was filed by a NGO Sarthak (WP 562/2001). Indian Psychiatric Society and Indian Association of Private Psychiatry also represented themselves in these Writ petitions. The Supreme Court in its interim order in April 2002 directed to examine the feasibility of formulating uniform rules regarding public and private sector psychiatric institutions. Human right activist group and NGOs working in the field were also pressing for revision of the Act to ensure protection of the human right aspects of the mentally ill patients. One of them commented "the Mental Health Act is a statute which provides a procedure by which persons living with mental illness can be denied their liberty".

Major objection of the IPS to the MHA, $1987^{5,6}$ as summarized in IPS documents are as follows.

1. MHA, 1987 was not based on modern concept of psychiatry with all the attendant scientific and technological advancement which had impacted the management of psychiatric illnesses.

2. Definition of mental illness was unsatisfactory. It excluded Mental Retardation.

3. Definition of Medical Officer and Psychiatrist was unsatisfactory as it had to be either a gazetted medical officer in service of the Government in the case of former or any medical practitioner to be declared so in the case of latter.

4. Only Government run and not privately run general hospitals providing psychiatrist service were exempted from the provisions of MHA, 1987.
5. In MHA, 1987 legal considerations were given too much weightage, whereas, medical consideration was given too little importance.

6. A Judicial Officer could determine the presence and nature of mental illnesses in people, by personally 'examining' them (diagnosing someone with mental illness requires special training and anybody without that could not be entrusted with that responsibility).

7. The licensing procedures were found cumbersome.

8. Nonprofessionals had the access to the confidential records of the patients in the name of inspection.

9. Inspection and licensing was applicable to mental hospitals and nursing homes even where those admitted were under the supervision of patient's family, which was consulted for all treatment decisions.

10. Central and State Mental Health Authorities were constituted by the Government, which had set up most of the mental hospitals mainly providing custodial care. This was in conflict with one of the objectives of the MHA viz. to regulate the powers of the Government for establishing, licensing and controlling psychiatric hospitals and psychiatric nursing homes for mentally ill persons.

11. No budgetary provisions were made available for the functioning of Central or State Mental Health Authority.

12. The Act had nothing to suggest the role of family in the care of mentally ill subjects.

13. Although there were provisions for delegating powers to the police officer with respect to bringing the homeless wandering mentally ill for treatment, there was no provision for penalizing the police if it failed to do so. 


\section{PROPOSED DRAFT OF AMENDMENTS TO MHA-1987 7,8}

India signed United Nations' Convention on Rights of Persons with Disability (UNCRPD), which was ratified by the Government of India in May, 2008. It became imperative for the Government to revise all related law on mental health and disability to bring them in harmony with UNCRPD. A National Consultation on the Mental Health Programme was held on 22nd January 2010 with the objective to review and identify gaps in the Mental Health Programme and actions to fill up these gaps. It was felt that the MHA 1987 needs amendments. It should move towards supporting, promoting and protecting the rights of persons with mental illness. Centre for Mental Health Law \& Policy, ILS College, Pune was given the responsibility of preparing the draft of the proposed legislation and present it to the Ministry of Health and Family welfare after having nationwide consultation on it. The first draft was circulated on 28-02-10 and after seeking objections and suggestions on the draft, a revised draft was released on 23-05-10. A series of regional and national consultation is planned before the final draft is presented to the Ministry. The salient features of the proposed draft are as follows.

1. Persons with mental illness - The nomenclature has been changed from 'mentally ill person' to 'person with mental illness'. Similarly 'mentally ill prisoner' has been replaced by 'prisoner with mental illness'. It is stated that language has a role in stigma associated with any condition. Hence 'persons with mental illness' is preferred to the term 'mentally ill person'.

2. Statement of objects and reasons - By definition the Act is stated to protect promote the rights of persons with mental illness. It is stated to create access to treatment, care and rehabilitation and to fulfill the obligations under the Constitution of India and obligations under various International Conventions. It is also stated to ensure that care, treatment and rehabilitation is provided in the least restrictive manner that does not intrudes on the right and dignity of the person. One of the objects of MHA -1987 which is dropped is 'to protect society from the presence of mentally ill persons who have become or might become a danger or nuisance to others'. Facilitation of integration of persons with mental illness into community life is also stated to one of the objects.

3. Mental Health Facility - Psychiatric hospitals and Psychiatric Nursing homes have been described as 'Mental Health Facility'. It is defined to include all facilities either wholly or partly meant for the care of the persons with mental illness, where persons with mental illness are admitted or reside at for care, treatment, convalescence and/or rehabilitation, either temporarily or otherwise and includes general hospital or general nursing home established or maintained by the Government or any other person. It is obvious that Psychiatric OPD services are not covered by this definition. There is an exclusion criteria which specifies that if the person with mental illness resides with his family, the place will not be regarded as mental health facility and thus exempt from registration. The definition is intended to cover non-medical institutions also, if the persons with mental illness are residing for care, convalescence or rehabilitation.

4. Mental Health Professionals - A new category of 'Mental Health Professional' has been created which includes psychiatrist, 
clinical psychologist, psychiatric social worker and registered mental health nurse. It is said that the category is created to facilitate involuntary admissions under section 19 of the Act. But they can become professional members in Mental Health Review Commission (MHRC) and also in Central and State Mental Health Authority.

5. Nominated Representative - A new concept of 'nominated representative' has been introduced and a person who has attained the age of 18 years and is competent to do so has the right to appoint a nominated representative and it can be communicated either verbally or in writing to the person in charge of the person's medical care. If no nominated representative has been appointed, family member as described in section $2(t)$ will be the nominated representative. If no family members are available, 'carer' (who is not a relative but who normally resides with the person and/or predominantly responsible for providing care to that person) will be the nominated representative. In certain cases nominated representative can be appointed by MHRC also.

6. Mental Illness - It has been defined as a substantial disorder of mood, thought, perception, orientation or memory which grossly impairs a person's behavior, judgment and ability to recognize reality or ability to meet the demands of normal life and includes mental conditions flowing from the use or abuse of alcohol and drugs, but excludes mental retardation. It is stated that the mental illness has been defined for the purpose of the Act in behavioral terms so that it can be understood by non-professionals also. It is obvious from this definition that if the disorder does not involve gross impairment of patient's insight and reality testing, the provisions of MHA will not apply and the disorders can be treated in normal 'doctor-patient' relationship. Thus neurotic and similar types of illnesses are excluded. Mental Retardation has been excluded from the ambit of the definition. It is pertinent to note here that the National Trust Act covers four illnesses i.e. mental retardation, autism, cerebral palsy and multiple disabilities. It was suggested that WHO definition as given in ICD should be adopted. But if it is adopted all psychiatric illnesses will come into the ambit of MHA.

7. Registration of Mental Health Facility Licensing has been replaced with registration and for registration, every mental health facility shall fulfill the minimum standards of facilities, minimum qualifications for the personnel, provisions for maintenance of records and reporting and any other conditions as may be prescribed. The registration will be done by State Mental Health Authorities and the application may be furnished in person or by post or online. The Authority within a period of 10 days and without any inquiry issue a provisional certificate of registration, which shall be valid for 12 months from the date of issue and shall be renewable. Permanent registration, which shall be valid for 36 months, shall be granted only when a mental health facility fulfills the prescribed standards for registration by the State Government. Mental health facility shall be classified into different categories and different standards may be prescribed for them. If at any time after registration the SMHA is satisfied that the conditions of registration are not being met or the persons entrusted have been convicted of an offence under this Act or persistently violating the rights of the Persons with mental illness, a show cause notice may be issued. If even after giving reasonable opportunity to the mental health facility, the Authority is satisfied that there has been breach of Rules under this 
Act or persistently violating the rights of persons with mental illness, the registration of the mental health facility may be cancelled. The Authority shall have right to cause an inspection of or inquiry in respect of any mental health facility, the result of which shall be communicated to the mental health facility. The Authority can issue any directions as it may deem fit and the mental health facility shall have to take action to the satisfaction of the Authority. The Authority or any person authorized by it may enter and search in manner prescribed by the authority at any reasonable time if there is any reason to suspect that anyone is running a mental health facility without registration. Any person aggrieved by any order of the Authority may appeal to the High Court of the State.

8. Inspecting officers and Visitors - Provisions of inspection at anytime by the Inspecting Officer (Sec 13), provisions of visitors for every mental health facility (sec 37 and 38) have been dropped in the draft.

9. Admission to a Mental Health Facility There are four types of admissions under the proposed draft - Independent admission, Admission of a minor, Supported Admission up to 30 days and Supported admission beyond 30 days.

a) Independent admission - Any person who is not a minor and consider himself to have a mental illness may request the medical officer in charge of a mental health facility to be admitted. The medical officer in charge will admit him if he is satisfied that person has a mental illness of sufficient severity and he will benefit from admission. An independent shall not be given treatment without his/ her informed consent and he may discharge himself from the mental health facility without the consent of the medical officer in charge. But a mental health professional may prevent discharge of an independent patient seeking discharge for 24 hours to allow assessment by two mental health professionals necessary for supported admission under sec 19 of the Act, if the necessary conditions are met.

b) Admission of a minor-A minor shall be admitted only in exceptional circumstances on application in writing of the nominated representative of the minor. Two mental health professionals, at least one of whom is a psychiatrist or one psychiatrist and one registered medical practitioner shall have to independently examine the minor and both conclude that the minor has a mental illness of sufficient severity, it is in the best interest of the minor, his mental health care needs of the minor cannot be met unless he/she is admitted and all community based alternatives have been shown to have failed or demonstrably unsuitable to the needs of the minor. It is also specified that no irreversible treatment can be provided for the mental illness of a minor. If the nominated representative of the minor no longer supports admission of the minor, he must be discharged. All admissions of minors beyond 30 days must be informed to MHRC and every subsequent 30 days continuation of admission requires approval from the MHRC.

c) Supported admission up to 30 days - A person with mental illness may be admitted in a mental health facility, 
if two professionals, one psychiatrist and the other being a mental health professional or a registered medical practitioner, each of them have independently examined in the preceding 7 days and both conclude that the person has a mental illness has recently threatened or attempted or is threatening or attempting to cause bodily harm to himself/herself and/or to another person and/or recently behaved or is behaving violently towards another person and/or has recently shown or is showing lack of competence to care for himself/ herself and the mental health professionals certify that admission to the mental health facility is the least restrictive option. The admission under this section shall be limited to 30 days. At the end of 30 days he will cease to be admitted under this section or continue to be admitted as an independent patient or continue to remain admitted under section 20, according to whatever criteria are met at the end of 30 days. If it is assessed even earlier that the criteria as described under this section are no longer met, the medical officer in charge will terminate the admission.

d) Supported admission beyond 30 days If the person is already admitted under section 19 and the criteria of admission as described above are still valid, the person will have to be independently examined by two psychiatrist in the preceding 7 days and if both certify that admission in the mental health facility is the least restrictive option possible, the person will remain admitted in the facility. But all admissions under this section must be approved by the MHRC within a period of 60 days from such admission or renewal becomes effective. Admission under this section will be limited to 180 days. Further admission beyond 180 days can be renewed for 180 days at each instance upon application of the nominated representative and by following procedures as above.

10. Emergency Treatment_- Under section 20.1, treatment can be initiated by any registered medical practitioner with the consent of nominated representative in certain specified emergency situations, at any health facility or in the community. But the treatment under this section will be limited to 72 hours and ECT and irreversible treatments shall not be provided under this section. What constitutes irreversible treatment is not specified.

11. Prohibited Treatments - ECT without the use of muscle relaxants and anesthesia and sterilization of persons with mental illness intended for treatment of mental illness is prohibited in the proposed draft. Psychosurgery may only be performed on approval of SMHA

12. Restrains and Seclusions - It is stated that person with mental illness cannot be chained in any manner whatsoever. Restrains and may only be used if it is authorized by the psychiatrist at the mental health facility and may be used no longer than necessary.

13. Duties of police officers and order in case of person with mental illness cruelly treated Police officers have been assigned duties to take any wandering person with mental illness to the nearest public mental health facility within a period of 24 hours and the duty of police officer once the person have been conveyed to the facility. In case any person with mental illness is cruelly treated or not under proper care, a police officer or any private person may report the fact to a Magistrate, who will pass appropriate order for proper care of the person after following the specified procedure or may order for conveying the person to a mental health facility for assessment and treatment as per other provisions of the ACT.

14. Mental Health Authorities - Central Mental Health Authority established by the Central Government, in addition to earlier function will also maintain an all India register of mental health 
facilities and mental health professionals and will also co-ordinate programs run by different ministries. Similarly State Mental Health Authority, in addition to earlier functions, will be in charge of registration of mental health facilities in the State. It has also been assigned duty to register certain mental health profession and make rules and criteria in that respect.

15. Mental Health Review Commission_- It will be a judicial body established by the State Government to perform various functions under the Act. President of the MHRC will be a person qualified to become a High Court Judge. There shall be three types of members - Judicial members, Professional members (any mental health professional can be the professional member) and representatives of users or carers and their organizations or NGO working in the field. MHRC may have as many panels in districts depending upon the workload. The panel shall be constituted by the President of the MHRC and shall consist of three members, judicial member, professional member and representative of users or carers or NGOs working in the field. Appeal against the decision of the MHRC shall lie to the High Court.

16. Protection of Rights of Persons with Mental Illness - There is a separate chapter dealing with these rights. It states that persons with mental illness cannot be subjected to cruel, inhuman and degrading treatment and their living environment will be safe and hygienic, with adequate provision of food, facilities for recreation, privacy etc. They shall not be subjected to physical or sexual abuse or forced to compulsory work. There will be non-discrimination in respect of medical insurance and in respect of emergency medical services or any other health services. Free and informed consent is required from them in case research works. If they are unable to give free consent, permission will have to be obtained from SMHA. Persons with mental illness or their nominated representative shall have right to information and right to confidentiality and shall in general be given access to their medical records. But the psychiatrist may withhold information in case of likelihood of harm to the person with mental illness or to other persons.

17. Advance Directives - Every person has a right to make written statement specifying the way the person wishes to be cared for and treated for a mental illness and the individual or individuals he wants to be appointed as his nominated representative or special personal representative. The advance directive should also be signed by a medical practitioner certifying that the person is competent and aware of what he is doing. It may be amended or cancelled by the person who has made it. An appeal can be made by the MHRC for overruling the advance directive.

18. Special Support Arrangements - MHRC may require create special support arrangements in case of persons with long term mental illness requiring very high level of support in decision making. MHRC can also appoint the nominated representative as Special Personal Representative if it is satisfied that all conditions exist and it is in the best interest of the person. Special Personal Representative will be a time limited arrangement, who will decide on behalf of the person in his/her personal matters and property except marriage, sexual relations and voting rights.

\section{CONCLUSION}

Many objections were raised on provision of the draft. Some of them insisted on adoption of the WHO definition of the mental illness and inclusion of mental retardation. The concept of nominated 
representative, carer, inclusion of general hospital psychiatry unit (GHPU) in mental health facility, recognition of so many professionals as mental health professional and prohibition of unmodified ECT were also objected. Advance directive and special personal representative were also the subjects of objection. IPS also insisted for recognition of role of family in care of persons with mental illness and introduction of open and closed ward concepts. Constitution of Central and State Mental Authority was seen to be heavily loaded by non-professionals. In constitution of MHRC also, psychiatrists are not given due weightage. Human right activist groups protested about dismantling of specific adjudicatory and monitoring power to judiciary and abolition of board of visitors. One of them called it 'Total Empowerment of Psychiatrist Act 2010'. The Act is still in process of consultation at the time of writing this article and comments to the draft may be posted to amendmentstomha1987@gmail.com.

It seems that the objectives of the psychiatrists and human right activist groups are at variance to each other. But primary concern for everyone should be the interest and welfare of the persons with mental illness. Mental Health Act is the Act meant for the persons with mental illness. Naturally, it should be directed towards betterment of their conditions and protection of their rights. But the protection should not be so overstretched that their welfare and proper care is endangered. It is in the interest of everyone if in the new Act, the emphasis is on ensuring easy availability of psychiatric treatment to all, finding ways to promote opening of more and more psychiatric inpatient facility, providing for better care of wandering persons with mental illness and protecting and promoting rights of persons with mental illness.

\section{REFERENCES}

1. Beotra, B.R (1965) Indian Lunacy Act, 1912 (Central \& States) with 1971 supplement. Law Book Co., Allahabad.

2. Dutta, A.B. (1987) - Mental Health Act, 1987: A Critical Approach, Proceedings of Workshop on Ethics in Psychiatry, 117-147, KG Medical College, Lucknow.

3. Dutta, A. B. (2001) - The Long March of Mental Health Legislation in Independent India; Dr. L. P. Shah Oration delivered at IPS-WZ Conference at Goa, published by Goa Psychiatry Society.

4. Dhanda, A (2010) - Status Paper on Rights of Persons living with Mental Illness in the light of the UNCRPD, in Harmonizing Laws with UNCRPD, Report prepared by the Centre for Disability Studies, NALSAR University of Law, Hyderabad

5. Government of India (1987) - The Mental Health Act; published by Delhi Law House in 2002.

6. Das, S.K. (2002) - The Mental Health Act 1987 and Current Issues; Presidential Address delivered at IPS - EZ Conference at Patna, 2002.

7. Pathare, S. and Sagade, J. (2010) - Working Papers on Amendments to MHA-1987 prepared on behalf of Ministry of Health, GOI, Centre for Mental Health Law and Policy, Indian Law Society, Pune.

8. Pathare, S. and Sagade, J. (2010) - Amendments to MHA-1987 - Draft dated 23-05-10 prepared on behalf of Ministry of Health, GOI, Centre for Mental Health Law and Policy, Indian Law Society, Pune. 